was between 1 and 3 P.M. On the following day some specimens were noticed; on the third day there were none to be seen, but for several days after occasional specimens were seen on the Corylus leaves about a quarter of a mile away.

\title{
NOTES ON UNCOMMON COLEOPTERA
}

\author{
By C. A. Frost \\ Framingham, Mass.
}

Melanotus tcenicollis Lec. Three specimens of this Elaterid have been taken in the past 45 years at Framingham. One specimen on June 1, 1912, one on June 27, 1915, by sweeping in a meadow, and one on June 2, 1945, near the railroad yards a few hundred yards from my home.

Stenotarsus hispidus Hbst. Four specimens have been taken in recent years near here. One by sweeping on Sept. 23, 1933, two on June 10, 1939, and one by sifting on April 1, 1944.

Triplax macra Lec. Three exactly typical specimens were taken at Paris, Me. on June 29, 1945, on fungi on dead poplar. One typical specimen from Prince Edward Co., Ont. collected by Brimley is at hand, and another labelled, "Zebulon, Ga. 4-14-38. P. W. Fattig" seems to be a typical specimen. Two other specimens which were named by others for me appear to be entirely different and maybe undescribed.

Ephistemus apicalis Lec. This minute beetle which is attached rather loosely to the family Cryptophagidoe in the list is recorded from N.Y.-Ind. They appear in very large numbers in old grass piles in the layer just below the dry top one here in Framingham. My specimens are labelled: Sherborn, Oct. 8, 1933, Framingham, Sept. 11, 1910, and Framingham, May 29, 1931, under dead musquash. Specimens of what appear to be this species are at hand from Mineral Springs, Ind. and from McMinnville, Ore., March 1, 1935 and May 20, 1941.

Pachybrachys pubescens Oliv. This species was not recorded east of Watkins, N. Y. by Fall in his monograph of the genus. On June 10,1945, one specimen was taken on a red oak leaf at Natick, Mass. and another specimen escaped. 

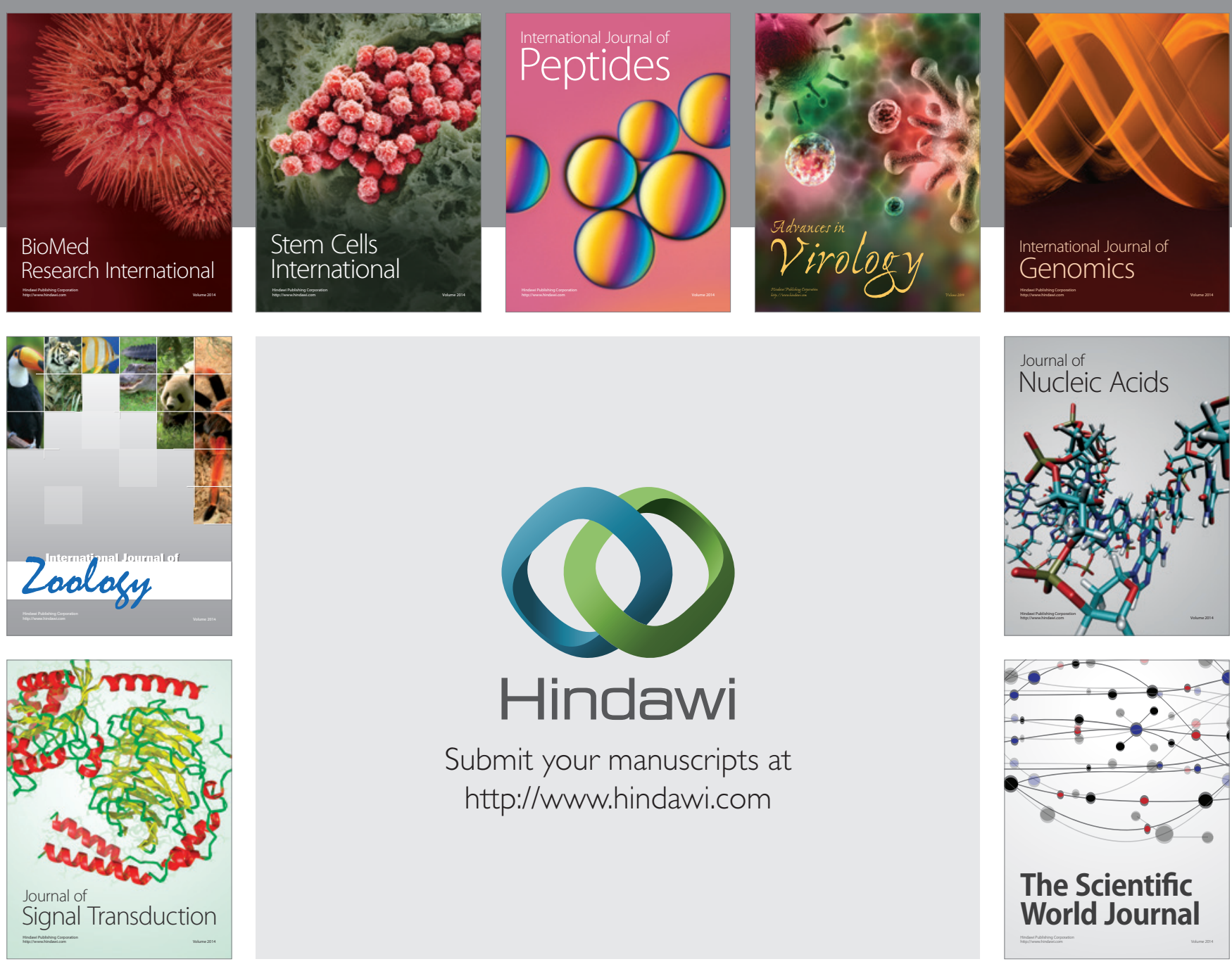

Submit your manuscripts at

http://www.hindawi.com
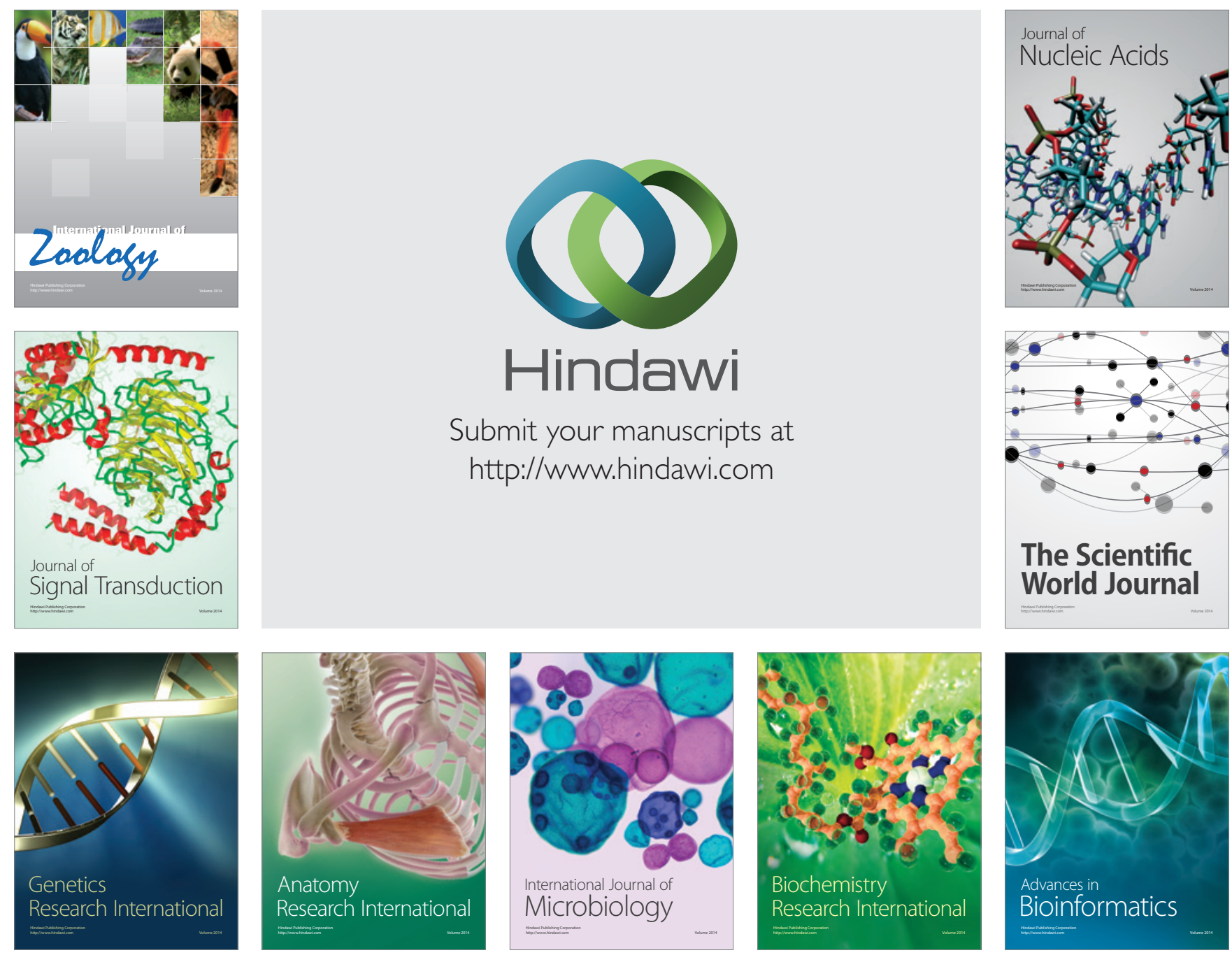

The Scientific World Journal
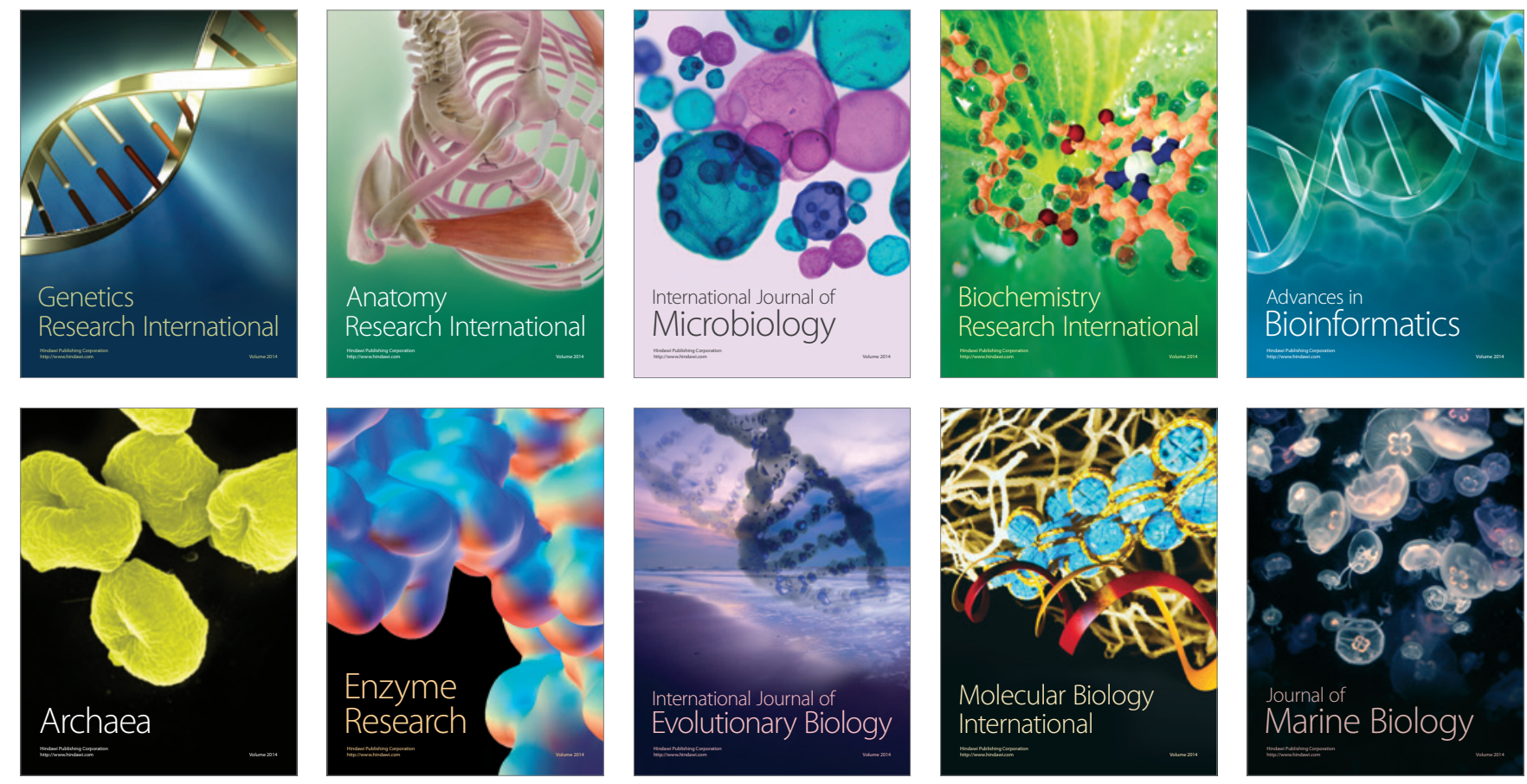